\title{
Study on Extended Scratch-Build Concept Map to Enhance Students' Understanding and Promote Quality of Knowledge Structure
}

\author{
Didik Dwi Prasetya ${ }^{1}$, Tsukasa Hirashima ${ }^{2}$, Yusuke Hayashi ${ }^{3}$ \\ Dept. of Information Engineering, Hiroshima University, Hiroshima, Japan 1, 2,3 \\ Dept. of Electrical Engineering, State University of Malang, Malang, Indonesia ${ }^{1}$
}

\begin{abstract}
Many studies reported that an open-ended concept map technique is a standard for reflecting learners' knowledge structure. However, little information has been provided that expands open-ended concept mapping to improve students' learning outcomes and meaningful learning. This study aimed to investigate the effects of Extended Scratch-Build (ESB) concept mapping on students' learning outcomes, consisting of understanding, map size, and quality of knowledge structure. ESB is an extended open-ended technique that requests students to connect a prior-existing original concept map with a new additional map on related material topics. ESB offers an expansion of concept maps by adding new propositions and linking them to previous existing maps to enhance meaningful learning. Twenty-five university students have participated in the present study. The collected data included a pre-test, post-test, delayed-test, map size, and quality of map proposition scores. The Wilcoxon signed-rank test was used to confirm the ESB performance. The statistical results indicated that ESB could improve meaningful learning through extended concept mapping approach and had a positive effect on students' learning outcomes. This study also emphasized that there was a correlation between the original and additional maps on students' learning outcomes.
\end{abstract}

Keywords-Concept map; open-ended; extended; knowledge structure

\section{INTRODUCTION}

Knowledge structure represents the organization and relationships among the components of a knowledge object [1]. The knowledge structure is constructed based on the learners' thoughts about the learning object characteristics and attributes from learning in the real world [2]. Determining students' knowledge structure is important for assessing what a learner knows about a domain of knowledge [3], [4]. Knowledge-based measurements are needed to express student performance and activities in various perspectives comprehensively. However, since knowledge is internal, and its representations are internal, it is not possible to measure these internal representations of knowledge directly [5]. Concept mapping techniques are a tool widely used by researchers to assess students' conceptual knowledge structures.

A concept map is a graphical tool for organizing and structuring knowledge in teaching, learning, and assessment [6], [7], [8], [9] introduced by Novak and Gowin [4]. Concept

This work was partially supported by JSPS KAKENHI Grant Number 19 H04227. map has been widely used in various fields and education levels, starting from preschool to higher education, and including corporate training [4]. As a powerful and flexible learning tool, the concept maps approach can be utilized in different disciplines and for various purposes, either individually or collaboratively. The concept map is now widely accepted as an instrument for the assessment of students' knowledge and is increasingly being embedded in computer-based environments [10], [11]. Computer-based concept mapping allows students to organize their knowledge easily, achieve deeper conceptual understanding, and encourage higher-level thinking. In particular, a computerbased program with Internet network support offers plenty of opportunities to practice concept mapping in an online learning environment.

Concept maps construction style can be classified into two categories: (1) open-ended or low-directed; and (2) closedended or high-directed [12], [13], [14]. Open-ended concept mapping allows learners to use any concepts and any linking words in their diagrams. The open-ended fashion gives full control to the learners to add, modify, or remove concepts and links that represent their knowledge understanding. Based on these characteristics, many researchers agree that the openended concept map is suitable for capturing the difference between the knowledge structures of the students accurately [14]. However, in the open-ended style, it will be more difficult to assess [13] and provide feedback to learners because there will be many variations of the concept map. On the other hand, a closed-ended concept mapping style contains finite concepts and links provided beforehand. In this case, learners must use the provided components to construct their maps by connecting one idea to another. Since the closedended technique uses the incomplete structure provided by the teacher, it allows automatic assessment and encourages students to achieve maximum understanding scores. However, closed-ended does not facilitate students to express their knowledge structure.

Previous studies have reported the practical use of openended concept maps for capturing students' knowledge structures. Some reasonably popular old studies argue that the open-ended technique is an appropriate standard for reflecting the differences among students' knowledge structures [6], [15]. Hartmeyer's investigation [16] discussed the results of a systematic review of concept mapping-based interventions in primary and secondary science education. The study suggested 
that open-ended concept maps suitable to evaluate students' knowledge and seemed appropriate for formative assessment. Wang et al. [17] studied a concept map-based learning environment with and without expert template support. The results suggested that the hyperlink support with constructing the map from scratch had a positive impact on the development of comparative strategies and enhanced learning. Tseng [18] studied compared the fill-in-the map (closedended) and the construct-the-map (open-ended) approaches on students' critical thinking skill development. The investigation results reported that the critical thinking skills scores of the open-ended group were better than students who used closedended method. Although researches on concept maps have been done a lot, little information has been provided that expands open-ended concept mapping to improve students' learning outcomes and meaningful learning.

Our previous study [19] had developed an Extended Scratch-Build (ESB) concept map tool in facilitating meaningful learning enhancement. ESB allows the students to extend their previous concept map by adding new propositions that are relevant to the material topic. Two phases of concept mapping become a single activity and characterize the ESB: Phase 1 and Phase 2. Phase 1 is an activity to construct a concept map based on learning material, while Phase 2 aims to expand the previous map by linking it to a new additional map. The present study investigated the effects of ESB on students' learning outcomes. The performance of ESB was evaluated using (1) test scores, (2) map sizes, and (3) quality of map propositions. Test scores were used to measure students' understanding and consist of pre-test, post-test, and delayed-test.

\section{LITERATURE REVIEW}

\section{A. Concept Maps}

Concept maps are recognized as a simple but powerful knowledge representation to support learners' and teacher's learning activity. Concept maps are simple because it can be represented by graphs, and just consisting of two symbols: nodes (points or vertices) represent concepts and links (lines or arcs) represent the relationships between concepts [12]. Concept maps considered a powerful knowledge representation because it shows measurable individual ideas. Concept maps are knowledge representations that are described through relationships between two ideas with linking words called propositions. Propositions are statements about some object or event in the universe [20], which can either be correct or incorrect. A proposition represents a unit's declarative or component of knowledge to form a meaningful statement. A proposition is the smallest semantic unit which connected to others as a unity and describes a particular meaning in concept maps.

Concept maps proposed by Novak and Gowin [4] based on Ausubel's assimilation theory, which emphasized meaningful learning. Meaningful learning can be defined as a process of linking new information to relevant previous knowledge in a cognitive structure [20]. Practically, meaningful learning is facilitated when students create concept maps by connecting one idea to another [21]. Meaningful learning (learning with understanding) is much stronger and longer-lasting than rote learning (learning with memorization) and requires individuals to have a well-organized knowledge structure to integrating new with existing knowledge [20]. Meaningful learning can be improved by linking prior concept maps to new related information in a hierarchically arranged structure [22]. The expansion of existing concept maps is a sound strategy for actualizing enhanced meaningful learning and promote good understanding.

The concept maps approach has been widely applied in the education environment to support and improve learning outcomes. In their research, Novak and Gowin [4] studied the concept map method that enables teachers to describe concepts that occur in particular texts and engage students actively in the learning process. A qualitative study conducted by Chan [23] showed how concept maps could be implemented in a problem-based learning class to enhance the students' creativity and to motivate them to learn and participate actively. Yue et al. [24] utilized a concept mapping in nursing education and indicated that it could affect the critical thinking affective dispositions and critical thinking cognitive skills of learners. A study by Sundararajan et al. [25] showed significant increases in critical thinking skills when learners engaged in collaborative concept mapping. Bernhardt and Roth [26] utilized a concept map to assess student learning and conclude that the participants were able to gain useful information about student learning in their material sections. Fischer et al. [27] assessed the effectiveness of using mechanistic concept maps (MCM) and reported that the experimental group got better reasoning skills and attitude comparing to the control group.

Concept maps as the students' knowledge representation can be assessed and evaluated quantitatively and qualitatively. The quantitative analysis focuses on measuring the number of concept map components or elements, such as concepts, links, propositions, and hierarchies [28]. Meanwhile, the quality analysis focuses on the scientific quality of concept maps on related topics [6], [29]. Many studies associated with the use of concept maps as assessment tools have employed scoring methods that emphasize accurate proposition [19], [30], [31], [32]. The reason for these arguments is because many researchers consider the proposition as the smallest and fundamental component of concept maps that represents the students' knowledge understanding. Proposition-based analysis validates the relationship between two concepts and produces better reliability of the other concept map components analysis [32], which provides a more effective statistical analysis.

\section{B. Extended Scratch-Build Concept Map}

Extended Scratch-Build (ESB) concept map is a graphical tool aimed to enhance meaningful learning and facilitate knowledge building [19]. ESB represents an interactive learning tool that provides dynamic responses according to the users' actions [33]. Students and teachers can use the ESB concept mapping in learning situations. However, teachers only have access to monitoring students' maps because the scoring method was done manually. The ESB tool can be implemented in various learning styles, including face-to-face or traditional learning, e-learning, and blended learning. 
ESB inspired by an open-ended concept mapping technique that experienced to capture differences across students' knowledge structures. An open-ended method is a potential approach to reflecting and measuring students' knowledge structure, but the achievement of understanding scores often cannot be maximized [6]. ESB attempts to offer an expansion of a two-phase concept map to improve students' learning outcomes. The main difference between ESB and other open-ended concept mapping tools is the expansion feature, which is a unity in map construction.

The expansion of the concept map provides opportunities for students to think more organized and is a realization of improved meaningful learning. As shown in Fig. 1, ESB provides a concept mapping feature consisting of two phases: Phase 1 and Phase 2. In Phase 1, students are asked to create a concept map in accordance with the first material or original map with an open-ended approach. Students are allowed to add concepts, links, and define propositions according to their understanding.

Furthermore, in Phase 2, students will expand the original concept map by adding new concepts, relationships, and propositions and linking them to the prior concept map. Unlike Phase 1, which started making concept maps from scratch, Phase 2 has provided an original map to be expanded according to additional material. In this situation, students were also allowed to modify their previous concept maps if necessary. In Phase 2, the final result of the individual map would be a combination of the original map and the additional map. However, the evaluation of the expansion of concept maps only considers additional maps, without including the original map.

A map expansion feature is an essential characteristic that identifies the ESB map and distinguishes it from other concept mapping tools. This expansion is also a strategy to realize improved meaningful learning. ESB approach not only realizes meaningful learning when students create concept maps but also enhances them through extended concept mapping. According to Cañas and Novak [21], meaningful learning is promoted when learners built concept maps, and this activity has been realized in Phase 1 of ESB. Furthermore, Phase 2 requested the students to extend the previous concept map, which also enhances the implementation of two-stages meaningful learning. The design of interconnected two-phases concept map construction provides more opportunities for students to improve their ideas and connect the new information to the existing knowledge structure. Efforts to expand the concept map by correlating new concept maps with current concept maps can be said to be improved meaningful learning.

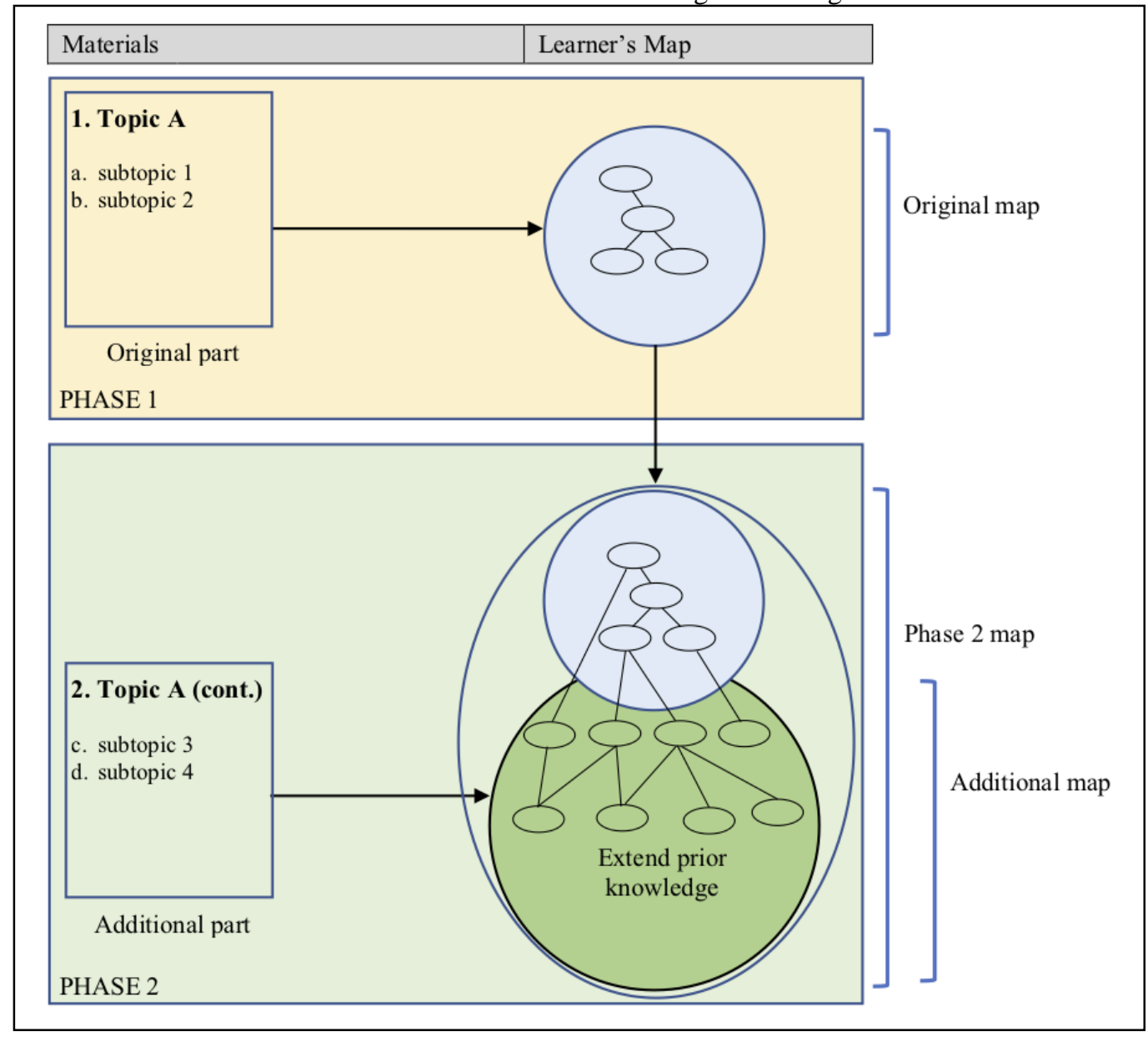

Fig. 1. The Practical flow of ESB Concept Map. 


\section{METHODOLOGY}

\section{A. Participants}

Participants in this study were Informatics Engineering students of the Department of Electrical Engineering, Faculty of Engineering, State University of Malang, Indonesia. A total 25 students (64\% male, $36 \%$ female) participated. This class is a regular class, and there were no significant age differences between students. Thus, data on age were not provided. Participants are students with a background in computer science and are accustomed to using information and communication technology in learning. However, none of the participants had any prior experience with the concept mapping method. This condition states that participants have comparable abilities.

\section{B. Context Material}

This study was conducted in the Database 1 course, which was delivered in Indonesian. This course is a compulsory subject that must be taken by informatics engineering students. The database subject consists of fundamentally complex concepts that require a practical approach to be easily understood by the students. This course was chosen because it is considered to be appropriate in the context of experimental concept mapping. Aside from being a compulsory course, the database is a discipline consisting of essential theories that must be well understood by students. This course also has prerequisites before and has links with advanced courses in the following semesters.

One of the conditions that must be fulfilled in meaningful learning is the material to be learned must be conceptually clear relative to the learner's prior knowledge. The relational database and SQL topic includes fundamental concepts that students must well understand thoroughly. This topic requires students to be able to identify broad general concepts and describe them into more specific relevant ideas.

The topic used in this experiment was SQL (Structured Query Language). The lecturer used presentation documents and distributed printed handouts to students. Following the offered experimental design, the material topic was divided into two parts: the original and additional parts. The original part is the material delivered by the lecturer in the first lecturing, while the additional part is an advanced material that was provided in the second teaching. Original and additional parts are the same subject material and were presented in one lecture session.

The presentation handout in the original material was composed of 532 words, while the additional material consisted of 829 words. As a reference, the lecturer defined the teacher's map, which includes 14 propositions for original material and 20 propositions for additional material. The teacher's map was only used as a reference when evaluating the quality of students' concept maps. The teacher's map was not used to compare the similarity of students' maps automatically because evaluations were done manually. A senior and experienced lecturer who had been teaching for 11 years was involved in this experiment to give a lecture and made an assessment.

\section{Experimental Settings}

This experiment was conducted in a computer laboratory during one lecture session. The lecture room provided facilities to support face-to-face learning and 30 personal computers connected to the Internet network. Participants used twenty-five personal computers, and the remaining five as a backup in case of trouble occurred. Each student was given an account as a unique identity to access the ESB application. The ESB application was run using a browser and accesses the server through an Internet network. A wired connection on a personal computer was provided to get a stable connection to the Internet network.

Before the experiment was conducted, in a previous course meeting, participants had been given an introduction to concept maps. The introduction topics included the definition, benefits, notation, and construction style of concept maps. Furthermore, participants were also instructed to build concept maps on the introduction of a database system topic. This step was also intended to ensure that all personal computers were able to connect to the server and work appropriately. After the demonstration well-conducted, at the next meeting, they carried out the experiment. The experimental activities follow the timeline, as described in Table I.

The total time of 100 minutes was required in one experiment session. Before starting the learning activities, the pre-test for the same topic material was given for $10 \mathrm{~min}$. After that, the lecturer distributed printed original material handouts, and she started the first lecture material with the traditional approach for $25 \mathrm{~min}$. In this activity, the lecturer explained the topic material using presentation documents, conducting discussions, and questions and answers as is faceto-face learning in class. In this situation, students engaged in learning and actively participated as usual. After the teacher explained the original part material, participants were asked to create a concept map related to the original material for 15 min. While creating the concept map, students were allowed to read their printed handouts that had been distributed. After the concept map creation time was completed, students uploaded the original map to the server.

TABLE I. THE EXPERIMENT SCHEDULE

\begin{tabular}{|l|l|l|l|}
\hline Phases & Teacher's activity & Students' activity & Duration \\
\hline 1 & Act as facilitator & Receive a pre-test & $10^{\prime}$ \\
\cline { 2 - 5 } & $\begin{array}{l}\text { Give a lecture with } \\
\text { original part material }\end{array}$ & $\begin{array}{l}\text { Following and } \\
\text { participate in lectures }\end{array}$ & $25^{\prime}$ \\
\cline { 2 - 5 } 2 & Act as facilitator & $\begin{array}{l}\text { Create a concept map } \\
\text { based on the original } \\
\text { material }\end{array}$ & 15 \\
\hline \multirow{5}{*}{2} & $\begin{array}{l}\text { Continue giving the } \\
\text { lecture with additional } \\
\text { part material }\end{array}$ & $\begin{array}{l}\text { Following and } \\
\text { participate in lectures }\end{array}$ & 25 \\
\cline { 2 - 5 } & Act as facilitator & $\begin{array}{l}\text { Expand the previous } \\
\text { concept map by } \\
\text { referring additional } \\
\text { material }\end{array}$ & 15, \\
\cline { 2 - 5 } & Act as facilitator & Receive a post-test & 10 \\
\cline { 2 - 5 } & Act as facilitator & $\begin{array}{l}\text { Receive a delayed-test } \\
(1 \text { week later })\end{array}$ & 10, \\
\hline
\end{tabular}


In Phase 2, the lecturer continued the lecture in accordance with the topic of the additional part material. The second lecture was carried out with the same approach and time allocation, which was $25 \mathrm{~min}$. Next, students were asked to construct a concept map based on additional material with the same time allocation as in Phase 1. The difference, if in Phase 1 , students built maps from scratch, in Phase 2, students would expand the original map and add new propositions according to the context material. This map extension will identify how many students can associate new propositions to propositions that already exist in the previous concept map. Furthermore, students would carry out on a post-test that includes original and additional material within $10 \mathrm{~min}$.

One week after the experiment was finished, students were given a delayed-test to investigate whether they still have good memory related to the topic of the material or not. In this delayed-test, students were only asked to do post-test questions that were given at random. Delay tests did not involve delay map construction, therefore only measure students' understanding. The delayed-test was done without prior notice, so students did not have the opportunity to read the material first.

\section{Measurements}

The performance of ESB on students' learning outcomes was investigated using three measurements: (1) test scores, (2) map sizes, and (3) quality of propositions scores. Pre-test, post-test, and delayed-test were chosen to assess students' understanding of SQL topics. Delayed-test was not only intended to investigate students' understanding, but also to express students' memory on the material topics. The lecturer designed evaluation questions with five answer choices. There were ten questions used to measure students' understanding consisting of 5 questions related to original part material and 5 questions related to additional part material. Pre-test, post-test, and delayed-test used the same questions that were delivered in random order. The lecturer who did the assessment was the same person who taught in the classroom.

Map measurement was performed based on propositions, which are the fundamental and smallest elements of the concept map that represent components of knowledge. The number of propositions was identified through the number of links connected to two concepts and forms a valid relationship. Proposition calculations were performed on all propositions made by each student, both scientifically correct and incorrect. This study considers all propositions with the reason they commonly describe student knowledge. Map size measurements evaluate the original and additional maps separately, then were analyzed statistically to identify their differences. The increment of concept map size was expressed through a comparison between the initial map and the final map as a result of the expansion. The final map was used is not a Phase 2 map, but an additional map, as described in Fig. 1. The size measurements are quantitative and calculated automatically by the system.

The map quality measurement was intended to complement previous quantity-based measurements. However, a measure of quantity is very likely irrelevant to the value of knowledge depth. The first quality measurement evaluates the quality of propositions using rubrics prepared by the lecturer. The quality of the propositions scoring method to examine the students' knowledge and understanding employed Osmundson et al. [29] rubric. Four levels of proposition scores were formulated, consisting of incorrect relationships ( 0 points), partially incorrect (1 point), correct but scientifically thin $(2$ points), and scientifically correct (3 points). Similar to the map size calculation, the quality measurements evaluated the original and additional maps separately and analyzed their differences. The proposition-based map scores were assessed manually by the lecturer, who gave a lecture in the classroom.

\section{E. Data Analysis}

The analysis was carried out on the results of the pre-test, post-test, delayed-test, map sizes, and proposition-based map scores. Since the present study involved small data in one group, no homogeneity tests were performed. The normality distribution was examined to determine whether the data could be analyzed using a parametric test. The normality distribution of data was tested using a Kolmogorov-Smirnov and ShapiroWilk test. Data were not normally distributed; therefore, nonparametric statistical tests were used to analyze study data.

A Wilcoxon signed-rank test was used to determine whether the mean of the pre-test scores was significantly different than post-test scores. The Wilcoxon signed-rank is a non-parametric analog of the parametric paired t-test. Wilcoxon statistical analysis was also used to measure the original map and additional map scores of students. Pearson's $r$ was also used as the effect size (ES) metric to examine the correlation coefficient. The Spearman's rank correlation coefficient was used to measure the strength of monotonic relationship values for each pair analysis. In all these analyses, a $p$-value $<0.05$ was deemed statistically significant. The value of Pearson correlation coefficients can be stated as small (.10), medium (.30), and large (.50) in terms of the magnitude of effect sizes.

\section{RESULTS}

\section{A. Analysis of Students' Understanding}

The pre-test was designed to measure the students' understanding of SQL topics before the intervention, and the post-test was used to investigate the students' understanding after the intervention. The delayed-test was applied to investigate students' retention regarding questions that have been given previously. Descriptive statistics of the pre-test, post-test, and delayed-test scores for the students are shown in Table II. The pre-test scores showed the achievement of students was still in the low category, with a mean value of 46.00. After giving lecture material and continued with the creation of concept maps and extended maps, the mean scores in the post-test increased to 80.00. A total of 3 students were able to reach a maximum score of 100 , although there were still two students who scored 50.

The Wilcoxon signed-rank test was used to compare the significance of the difference between pre-test and post-test scores statistically. The Wilcoxon signed-rank test compares the median difference between pairs. The results of the analysis reported that there were significant differences between pre-test and post-test scores $(Z=-4.314 ; p=.000<$ 
$.05)$ with a large effect size of Pearson's $r$ value $(r=0.61)$. Based on statistical analysis results, the giving of an intervention in the experiment showed a significant difference. A large effect size means that the difference between the pretest and post-test scores was great. Furthermore, Spearman's rank correlation coefficient was used to quantify the correlation between pre-test and post-test scores statistically. The correlation between the pre-test and post-test scores showed a significant difference $(p=.001<0.05)$ with a strong positive correlation coefficient $(r=.601)$.

The delayed-test was done a week after the experiment was finished and without any prior notice. Based on descriptive statistics in Table II, it can be seen that the delayed-test scores have decreased compared to the post-test scores. However, the average delayed-test scores were not different from the post-test scores. Likewise, compared to the pre-test scores, the performance of delayed-test scores was still superior. Fig. 2 shows the average achievement of students' pre-test, post-test, and delayed-test scores.

Further investigation was performed to find out the significance of the difference between post-test and delayedtest scores. The results of the Wilcoxon signed-rank test were reported that there were no significant differences between post-test and delayed-test scores $(Z=1,917 ; p=.06>.05)$ with a small effect size of Pearson's $r$ was 0.27 . The statistical analysis results stated that delayed-test scores achievement did not decrease significantly and had a small effect size. Therefore, even though the test results showed a decrease in performance, it still stated that students' have fairly good retention related to the material topics that were taught a week ago.

Furthermore, Spearman's rank correlation coefficient was used to observe the correlation between post-test and delayedtest scores. The statistic correlation results showed a significant difference $(p=.000<0.05)$ with a strong positive correlation coefficient $(r=.662)$. Thus there is a relationship between students' post-test and delayed-test scores. Students who had high scores on the post-test also obtained high scores on the delayed-test and vice versa.

\section{B. Analysis of Map Sizes}

The map size illustrates the broadness of the concept map represented by the number of definable propositions. The numbers of propositions for each student in the original map and additional maps were obtained from the system. Descriptive statistics of the number of propositions for original and additional maps are shown in Table III. In the original map, some students were able to achieve aboveaverage performance. Even the maximum score was also obtained by the student when making the original map. Nevertheless, the average number of additional map propositions was higher than the original map, which was 12.36 compared to 9.64 . These results showed that with the same time allocation, the expansion of the concept map was able to produce a more extensive map size than making a map from scratch.
Achievement of the individual map size scores on the original and additional maps is shown in Fig. 3. The map size results represented the characteristics of an open-ended concept map that facilitates students to express their knowledge. In Fig. 3, it appeared that the performance of each student varies, which illustrates the heterogeneity of student understanding in the Database topic. A total of 4 students obtained the map size scores on the original map higher than the additional map; 3 students received the same score between the original and additional map; and 18 students achieved higher map scores higher than the original map. The results of giving the intervention reported that students were able to expand their previous concept maps.

TABLE II. Descriptive Statistics of The PRE-Test, Post-Test, AND DELAYED-TEST SCORES

\begin{tabular}{|l|l|l|l|l|l|l|}
\hline Pairs & N & Min & Max & Median & Mean & SD \\
\hline Pre-test & 25 & 20 & 80 & 40.00 & 46.00 & 15.546 \\
\hline Post-test & 25 & 50 & 100 & 90.00 & 80.00 & 15.275 \\
\hline Delayed-test & 25 & 40 & 100 & 70.00 & 74.40 & 16.850 \\
\hline
\end{tabular}

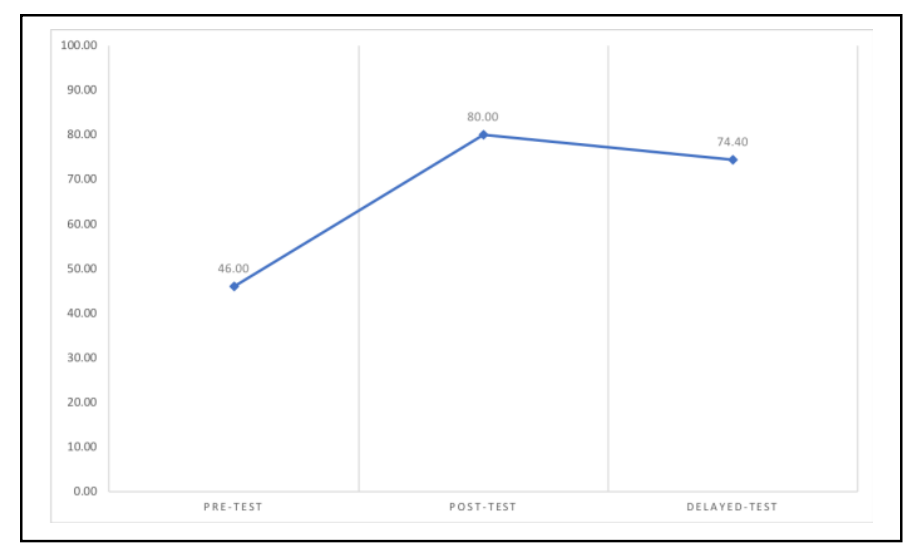

Fig. 2. Average Scores of Pre-Test, Post-Test, and Delayed-Test.

TABLE III. DESCRIPTIVE STATISTICS OF THE NUMBER OF PROPOSITIONS SCORES

\begin{tabular}{|l|l|l|l|l|l|l|}
\hline Pairs & N & Min & Max & Median & Mean & SD \\
\hline Original map & 25 & 5 & 14 & 10.00 & 9.64 & 2.98 \\
\hline Additional map & 25 & 8 & 18 & 12.00 & 12.36 & 2.66 \\
\hline
\end{tabular}

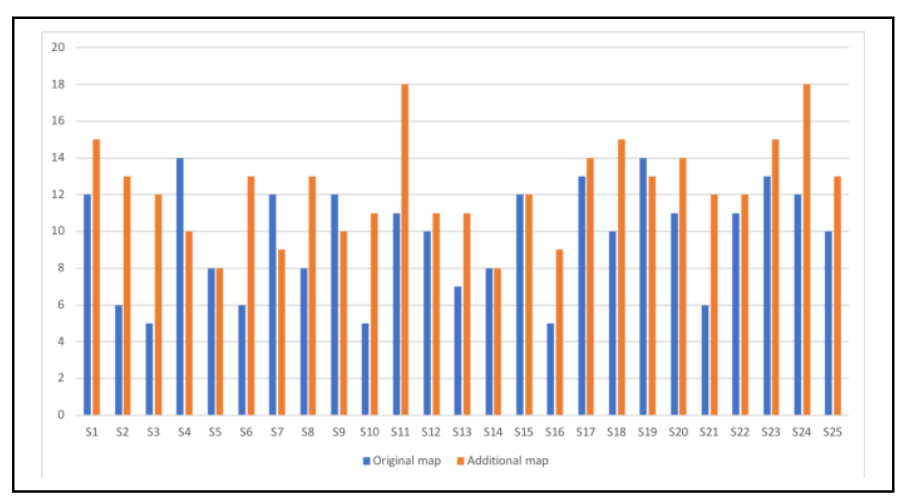

Fig. 3. Achievement of Map Size in Original and Additional Maps. 
The statistical analysis Wilcoxon signed-rank test was used to determine whether the map extensibility between the original and additional maps was significant. Based on a $p$ value threshold of 0.05 , there was a statistically significant difference between both concept maps $(Z=-3.190 ; p=.001<$ $.05)$ with Pearson's $r$ was -0.45 , showing a medium effect size. The analysis indicated that students were not only able to expand the existing concept map, but also reach a larger map size than the prior map. The Spearman's rank correlation coefficient was used to calculate the correlations between original and additional map sizes. The statistical analysis results indicated there was a weak positive correlation at $r$ of $.300(p=.145>0.05)$.

Although the number of propositions often illustrates the breadth of students' knowledge structure [34], this measurement can also be misleading because a large number of propositions does not mean that the students have a good understanding [35]. Likewise, the same number of propositions on two concept maps does not necessarily indicate the same knowledge. Therefore, qualitative measurements can be used, for example, by giving different weight values. This type of measure will be discussed further in the analysis of the quality of propositions.

\section{Analysis of Quality of Propositions}

In contrast to the map size analysis, which takes into account all propositions created by students, the calculation of the quality of propositions only considers correct propositions. The proposition-based map score was done by the lecturer manually by referring to the scoring rubric that has been defined. For each correct proposition, the lecturer gives a score of 1 , which states the lowest level of accuracy, a score of 2 with thin scientific correctness, and a score of 3 , which indicates the perfection with the highest scientific level. Table IV shows the descriptive statistics of the students' quality of propositions for original and additional maps. Student performance on the quality of propositions looks constant, as in the analysis of map size. The mean value on making the second map (additional map) was higher than the first map (original map).

Students' performance on the quality of propositions scores for original and additional maps are shown in Fig. 4. A total of 5 students obtained the map size scores on the original map higher than the additional map, while 20 students acquired the additional map scores higher than the original map. Similar to students' performance on map size, the quality of propositions results naturally describe the level of student knowledge. Although the distribution of student achievement was uneven, it was still dominated by students who have increased performance on the additional map.

TABLE IV. DESCRIPTIVE Statistics OF THE QUALITY OF PROPOSITIONS SCORES

\begin{tabular}{|l|l|l|l|l|l|l|}
\hline Pairs & N & Min & Max & Median & Mean & SD \\
\hline Original map & 25 & 14 & 48 & 24.00 & 24.88 & 8.941 \\
\hline Additional map & 25 & 10 & 52 & 30.00 & 31.32 & 11.257 \\
\hline
\end{tabular}

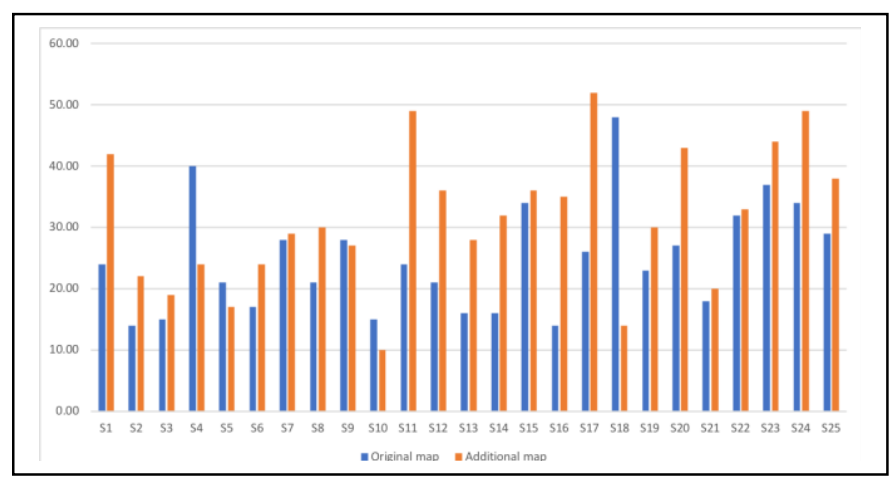

Fig. 4. Quality of Propositions Scores in Original and Additional Maps.

The Wilcoxon signed-rank test was applied to evaluate the significance of the difference in quality scores between the original map and the additional map. The results of the analysis showed a significant difference $(Z=-2.746 ; p=.006$ $<.05)$ with Pearson's $r$ of -0.39 , indicating a medium effect size. Next, Spearman's rank correlation coefficient was used to examine the association between the quality of propositions of original and additional maps. The correlation coefficient of the original and additional map was 0.4 , with a $p$-value of less than 0.05 . The $r$ of 0.4 indicated a moderate positive correlation coefficient.

Based on statistical analysis results, it can be seen that the quality of propositions in the additional map showed a significant increase. The ESB approach not only facilitates students to broaden and associate their knowledge but also attained higher quality. Additional map results were also known to be influenced by student achievement on the original map, which can be seen from the correlation between them.

\section{DISCUSSION}

\section{A. The Effects of ESB on Students' Understanding Scores}

Constructing an open-ended concept map technique is consider appropriate because it shows the difference between the knowledge structures of the learners [6], [13], and able to recall the basic terms in learning [36]. As is known, the openended approach allows students to express ideas according to their knowledge. Unlike reading learning material that consists of many concepts, the concept mapping approach helps students to identify core concepts. This situation tends to encourage them to have a good memory for related material topics.

Although some researchers reported that the open-ended approach is not able to achieve a maximum understanding score [6], the expansion of the concept map through ESB showed a bit different findings. Pre-test and post-test scores reported that teacher explanations supported by ESB concept mapping could significantly increase students' understanding. Likewise, with the delayed-test results, students still have a good memory of the material that was taught a week ago. This finding evidenced through the delayed-test scores, which was not significantly different from the post-test, despite a decrease in the average value of the group. 
The ESB strategy, which involved expanding concept mapping, had proven to be able to increase students' understanding regarding the material. The expansion of the concept map by linking new propositions to the existing map encourages students to improve their understanding. Students were asked to connect prior core concepts with new concepts. Thus, students can further increase focus and ignore other ideas that do not represent key concepts. Observations in the learning process reported that students who were still uncertain of the correctness of the propositions they had made would make use of the second teaching session to ask questions actively. Next, in the second concept mapping session, they had the opportunity to correct and add more new relevant propositions. This situation made ESB suitable for use to facilitate formative assessment in a classroom. As confirmed by Hartmeyer et al. [16], the open-ended concept mapping technique most appropriate for the formative evaluation.

\section{B. The Effects of ESB on Map Size}

The present study reported that ESB is an extensible concept mapping tool that can be expanded to produce a broader new related concept map. ESB facilitates students to extend the concept map by connecting the new knowledge structure to the existing concept map. According to previous studies [6], [14], the open-ended technique in ESB can reveal different knowledge structures across students. This condition was demonstrated through the achievement of original maps and additional maps that vary from one student to another. The experimental results also found that the average map size on the expansion experienced a significant increase.

In Phase 1 concept mapping, students were able to express their knowledge related to the topic of SQL material. Students could make a concept map based on the original part material as an example in Fig. 5. Although the average number of propositions successfully made by students was still below the propositions defined by the teacher, but had shown positive achievements. The results of creating the original map show that each student could express their knowledge naturally, as indicated by the achievement of a varied number of propositions. Fletcher et al. [37] argued that knowledge structure within groups illustrates variations of individual ideas according to their responsibility.

Phase 2 is a crucial stage that illustrates the main activities of ESB concept mapping. At this stage, students were allowed to expand the original map by adding new relevant propositions. Fig. 6 shows the results of an additional map of one of the students as an extension of the concept map. Students' performance was measured through map extensibility, which is the possibility that the map can be expanded and the size of the area increased. The results of the extensibility were measured through a map size comparison between the original map and the additional map.

The number of concept map components defined by students illustrates the amount of information collected and elaborated by them [38]. The existence of a prior existing map stimulates students to discover new concepts and relate them to defined concepts. Although they got the same time allocation, which was 15 minutes, students were able to expand the concept map following new material topics.

One important thing that was also found here was that the results of the expansion in the additional map showed an increase in map size and with a significant difference compared to the original map. Statistical analysis results indicated there was a weak positive correlation between the original map and the additional map. Although map size does not always describe good understanding, it shows a broad overview of students' achievements.

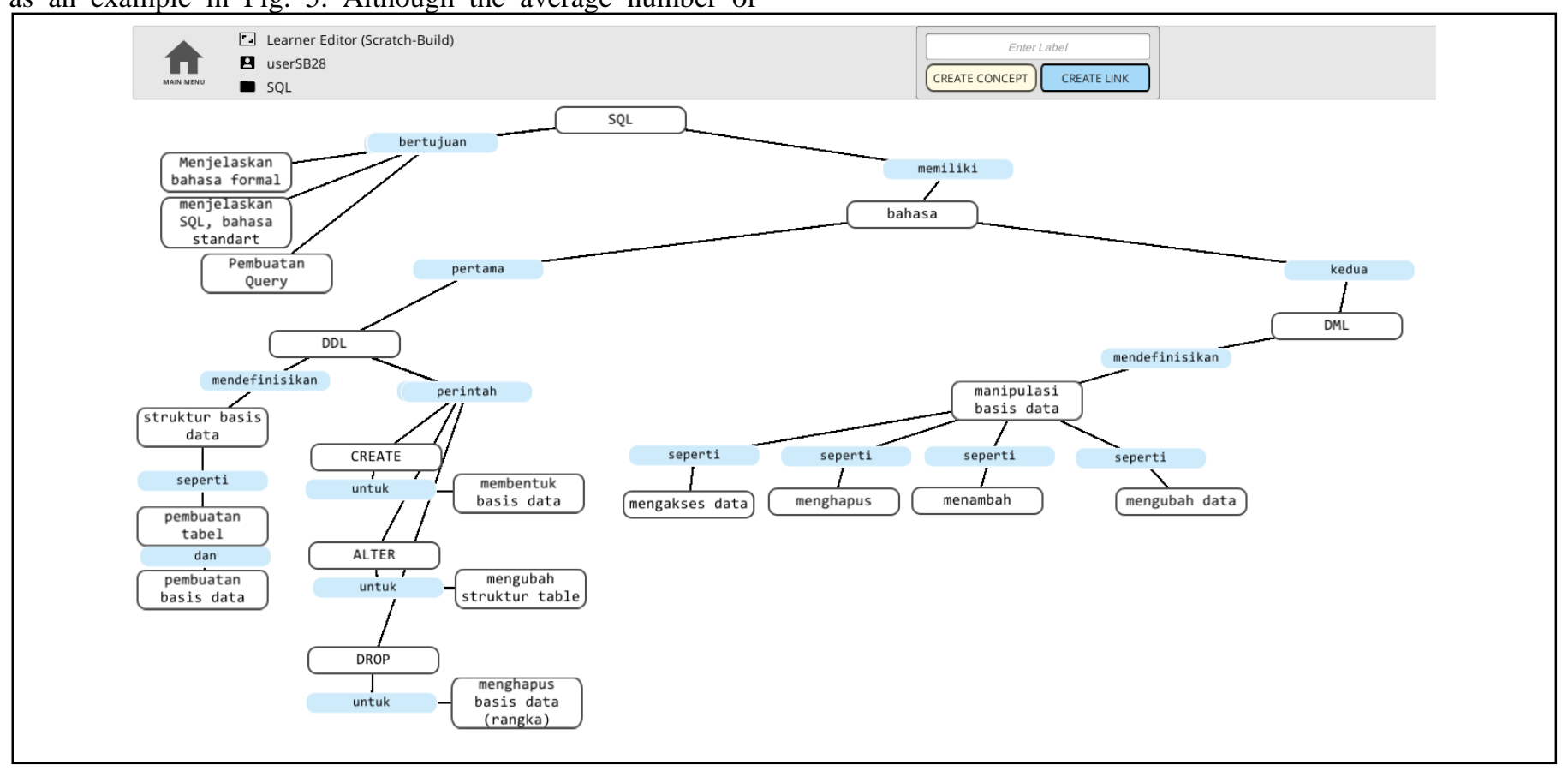

Fig. 5. The Original Map Results of a Student in Phase 1. 


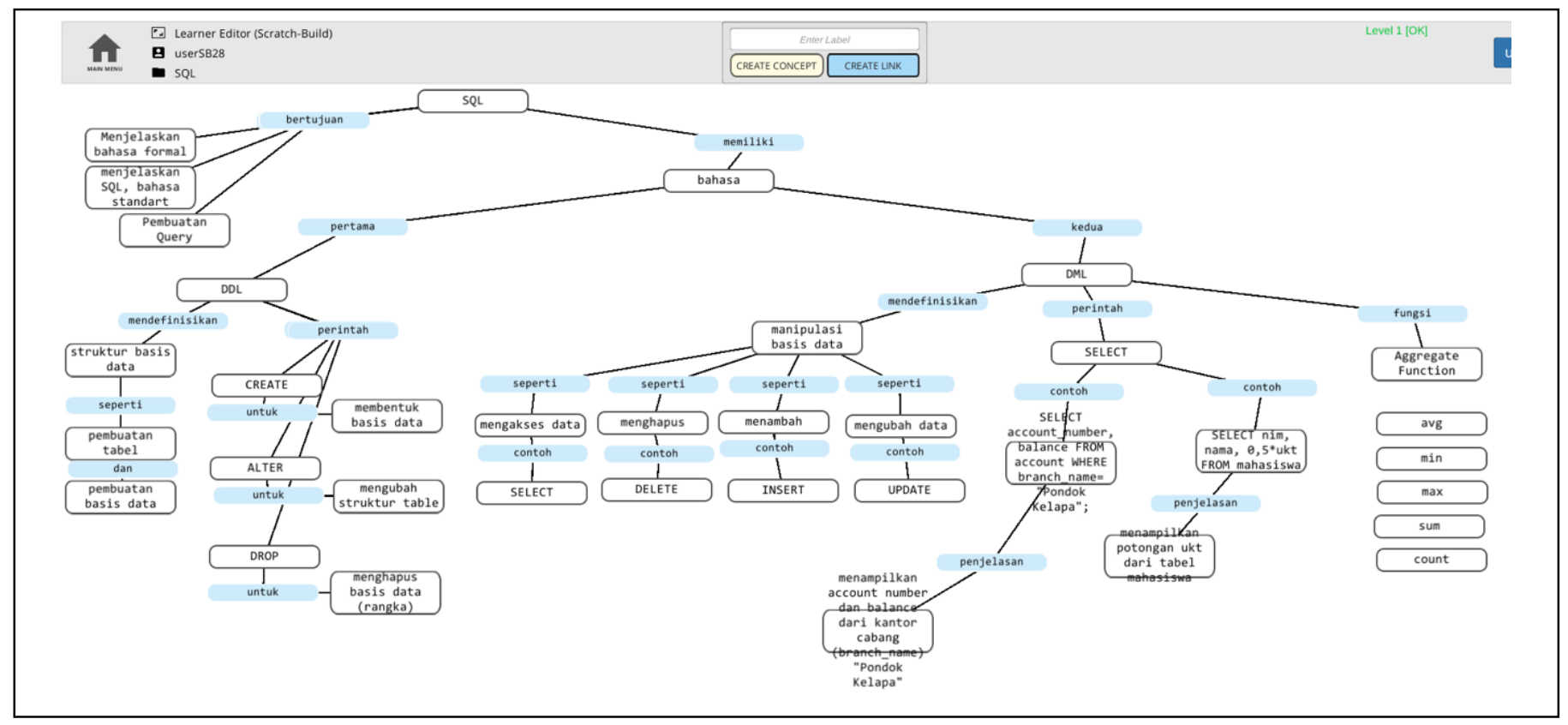

Fig. 6. The Additional Map Results of a Student in Phase 2.

\section{The Effects of ESB on Quality of Proposition}

The current findings showed that ESB not only facilitated students to increase the concept map size but also attained a higher quality of map propositions. Statistical analysis results emphasized that the quality of propositions scores in the additional map experienced a significant increase compared to the original map. This result was in line with the map size, which also shows an increase in scores. There are two possible explanations related to increasing student achievement, as discussed below.

First, creating the original map in Phase 1 by utilizing the open-ended approach encouraged students to express their knowledge independently. Students acquire the opportunity to find essential concepts according to their understanding. In this situation, they have the confidence to link one idea to another idea and produce a meaningful concept map.

Second, the expansion of the concept map on ESB provides opportunities for students to produce scientifically correct propositions. The existence of time lags in concept, making it encouraged students to be more active in class. In Phase 1, students built concept maps according to their knowledge. Furthermore, when the lecture resumed, some students seemed to use this moment to discuss with the lecturer and review their knowledge. Thus, in Phase 2, students have no difficulty in adding new propositions and linking them to existing original maps. In Phase 2, students also have the opportunity to correct propositions on the original map that are considered inappropriate.

Cañas and Novak [21] argued that concept mapping activity is a realization of meaningful learning. ESB not only facilitates students to realize meaningful learning when they built maps but also encourages them to enhance meaningful learning. Improved meaningful learning was expressed by linking pre-existing concept maps to new related knowledge [22]. Students have well-organized and relevant expertise to link further information to the existing concept map. It also states that the expansion of the concept map describes a broad overview of students' achievements [34]. The expansion of concept mapping provides two benefits for students, namely the opportunity to review their existing original maps and prepare relevant additional maps.

\section{CONCLUSION}

This study investigated the effects of Extended ScratchBuild (ESB) concept mapping on students learning outcomes, consisting of understanding, map size, and quality of propositions scores. The main contribution of the current study was to propose an ESB concept mapping approach and observed its effect on learning. ESB offers an expansion of concept maps by adding new propositions and linking them to prior existing maps to enhance meaningful learning. Experimental results reported that ESB had a positive effect on students' learning outcomes. The findings revealed that students' additional maps were able to achieve significantly increased map size and quality of propositions scores compared to the original map. This study also emphasized that there was a correlation between the original map and the additional map on students' learning outcomes.

This study involved several limitations that should be considered for further works. The students who participated in this experiment were relatively small. Future studies should find more significant participants and involved a control group in examining the ESB effects on learning. The pre-test, posttest, and delayed-test questions were used to assess the students' learning understanding were also relatively small. In the future, more design questions will be able to reveal a more comprehensive understanding of particular topics.

\section{ACKNOWLEDGMENT}

Thanks to the Islamic Development Bank (IsDB) for Ph.D. scholarship in partnership with Universitas Negeri Malang 
(UM), Indonesia. Also, huge thanks to Hirashima-Sensei in the Dept. of Information Engineering, Hiroshima University, Japan.

\section{REFERENCES}

[1] M. Merrill, "Knowledge objects and mental models," Proceedings International Workshop on Advanced Learning Technologies. IWALT 2000. IEEE 2000.

[2] S. Wu, A. Chang, M. Chang, T.-C. Liu, and J.-S. Heh, "Identifying Personalized Context-Aware Knowledge Structure for Individual User in Ubiquitous Learning Environment," Fifth IEEE International Conference on Wireless, Mobile, and Ubiquitous Technology in Education (wmute 2008), 2008.

[3] C. Nakiboglu, "Using word associations for assessing non major science students' knowledge structure before and after general chemistry instruction: the case of atomic structure", Chemistry Education Research and Practice, 9(4), 309-322, 2008.

[4] J. D. Novak and D. B. Gowin, "Learning how to learn". New York: Cambridge University Press, 1984.

[5] D. Ifenthaler, "Scope of graphical indices in educational diagnostics", Computer-based diagnostics and systematic analysis of knowledge (pp. 213-234). New York, NY: Springer, 2010.

[6] J. Vanides, Y. Yin, M. Tomita, and M. A. Ruiz-Primo, "Concept maps", Science Scope, 28(8), 27-31, 2005.

[7] E. Plotnick, "Concept mapping: A graphical system for understanding the relationship between concepts", (pp. 1998-1). Syracuse, NY: ERIC Clearinghouse on Information and Technology, 1997.

[8] T. Hirashima, K. Yamasaki, H. Fukuda, and H. Funaoi, "Framework of kit-build concept map for automatic diagnosis and its preliminary use", Research and Practice in Technology Enhanced Learning, 10 (1), 17, 2015.

[9] L. Zheng, X. Li, X. Zhang, and W. Sun, "The effects of group metacognitive scaffolding on group metacognitive behaviors, group performance, and cognitive load in computer-supported collaborative learning", The Internet and Higher Education, 42, 13-24, 2019.

[10] K. Weinerth, V. Koenig, M. Brunner, and R. Martin, "Concept maps: A useful and usable tool for computer-based knowledge assessment? A literature review with a focus on usability", Computers \& Education, 78, 201-209, 2014.

[11] S. B. Dias, S. J. Hadjileontiadou, J. A. Diniz, and L. J. Hadjileontiadis, "Computer-based concept mapping combined with learning management system use: An explorative study under the self-and collaborative-mode", Computers \& Education, 107, 127-146, 2017.

[12] Cañas, Alberto J., Priit Reiska, and Joseph D. Novak. "Is My Concept Map Large Enough?." International Conference on Concept Mapping. Springer, Cham, 2016.

[13] E. M. Taricani and R. B. Clariana, "A technique for automatically scoring open-ended concept maps", Educational Technology Research and Development, 54(1), 65-82, 2006.

[14] T. Hirashima, "Reconstructional Concept Map: Automatic Assessment and Reciprocal reconstruction", The International Journal of Innovation, Creativity and Change (IJICC), 5 (5), 669-682, 2019.

[15] Y. Yin, J. Vanides, M. A. Ruiz-Primo, C. C. Ayala, and R. J. Shavelson, "Comparison of two concept-mapping techniques: Implications for scoring, interpretation, and use", Journal of Research in Science Teaching: The Official Journal of the National Association for Research in Science Teaching, 42(2), 166-184, 2005.

[16] R. Hartmeyer, M. P. Stevenson, and P. Bentsen, "A systematic review of concept mapping-based formative assessment processes in primary and secondary science education", Assessment in Education: Principles, Policy \& Practice, 25(6), 598-619, 2018.

[17] S. Wang, D. Sonmez Unal, and E. Walker, "MindDot: Supporting Effective Cognitive Behaviors in Concept Map-Based Learning Environments", In Proceedings of the 2019 CHI Conference on Human Factors in Computing Systems (pp. 1-14), 2019.
[18] S. S. Tseng, "Using Concept Mapping Activities to Enhance Students' Critical Thinking Skills at a High School in Taiwan", The Asia-Pacific Education Researcher, 1-8, 2019.

[19] D. D. Prasetya, T. Widiyaningtyas, S. C. Putro, T. Hirashima, and Y. Hayashi, "Extended Scratch-Build Concept Map to Enhance Meaningful Learning", International Conference on Electrical, Electronics and Information Engineering (ICEEIE) (Vol. 6, pp. 187-191), IEEE, 2019.

[20] J. D. Novak and A. J. Cañas, "The theory underlying concept maps and how to construct and use them", 2008.

[21] A. J. Cañas and J. D. Novak, "Concept mapping using CmapTools to enhance meaningful learning", In Knowledge cartography (pp. 23-45). Springer, London, 2014.

[22] R. Boffey, P. Gerrans, and S. Kennedy, "Using digital lectures to assist student learning", eCULTURE, 3(1), 17, 2010.

[23] Z. C. Chan, "A qualitative study on using concept maps in problembased learning", Nurse education in practice, 24, 70-76, 2017.

[24] M. Yue, M. Zhang, C. Zhang, and C. Jin, "The effectiveness of concept mapping on development of critical thinking in nursing education: a systematic review and meta-analysis", Nurse education today, 52, 87-94, 2017.

[25] N. Sundararajan, O. Adesope, and A. Cavagnetto, "The Process of Collaborative Concept Mapping in Kindergarten and the Effect on Critical Thinking Skills", Journal of STEM Education, 19(1), 2018.

[26] K. S. Bernhardt and M. J. Roth, "Using concept maps to assess student learning in a multi-section introduction to engineering course", ASEE Annual Conference and Exposition Proceedings, 2018.

[27] K. Fischer, A. M. Sullivan, E. Krupat, and R. M. Schwartzstein, "Assessing the effectiveness of using mechanistic concept maps in casebased collaborative learning", Academic Medicine, 94(2), 208-212, 2019.

[28] C. Nakiboğlu and H. Ertem, "Comparison of the structural, relational and proposition accuracy scoring results of concept maps about atom", Journal of Turkish Science Education, 7(3), 60-77, 2010.

[29] E. Osmundson, G. K. W. K. Chung, H. E. Herl, and D. C. Klein, "Knowledge mapping in the classroom: A tool for examining the development of students' conceptual understandings" Report: CSE-TR507, 1999.

[30] J. Pailai, W. Wunnasri, K. Yoshida, Y. Hayashi, and T. Hirashima, "Kitbuild concept map with confidence tagging in practical uses for assessing the understanding of learners", Int. J. Adv. Comput. Sci. Appl, 9(1), 79-91, 2018.

[31] I. M. Kinchin, A. Möllits, and P. Reiska, "Uncovering Types of Knowledge in Concept Maps", Education Sciences, 9(2), 131, 2019.

[32] T. Stoddart, R. Abrams, E. Gasper, and D. Canaday, "Concept maps as assessment in science inquiry learning a report of methodology", Int. J. Sci. Educ.,22(12), 1221-1246, 2000.

[33] D. D. Prasetya, A. P. Wibawa, and T. Hirashima, "An interactive digital book for engineering education students", World Transactions on Engineering and Technology Education., vol. 16, no. 1, pp. 54-59, 2018.

[34] T. Stoddart, "Using concept maps to assess the science understanding and language production of English language learners", Proc. of the Second Int. Conference on Concept Mapping, 606-6012, 2006.

[35] A. J. Cañas, L. Bunch, J. D. Novak, and P. Reiska, "Cmapanalysis: An extensible concept map analysis tool", Journal for Educators, Teachers and Trainers, 2013.

[36] R. B. Clariana, "Deriving individual and group knowledge structure from network diagrams and from essays", In Computer-based diagnostics and systematic analysis of knowledge (pp. 117-130), Springer, Boston, MA, 2010.

[37] J. D. Fletcher and R. A. Sottilare "Shared mental models in support of adaptive instruction for teams using the GIFT tutoring architecture", International Journal of Artificial Intelligence in Education, 28(2), 265285, 2018.

[38] R. B. Clariana, T. Engelmann, and W. Yu, "Using centrality of concept maps as a measure of problem space states in computer-supported collaborative problem solving”, Educational Technology Research and Development, 61(3), 423-442, 2013. 